\title{
Spatial-temporal Distribution and Risk Analysis of Terrorist Attack Fires
}

\author{
Guohui Li, Cheng Wang, Lizeng Zhao, Weiping Han, Ying Wang \\ Tianjin Fire Research Institute of Ministry of Public Security, Tianjin 300381, China \\ 恐怖袭击火灾时空分布特征及风险分析 \\ 李国辉, 王澄, 赵力增, 韩伟平, 王颖 \\ 公安部天津消防研究所, 天津 300381 , 中国
}

\begin{abstract}
The word focused on the terrorist attack fires (TAFs). The frequency-fatality distribution and the spatial-temporal evolution of TAFs under the influence of targets, regions, and years were investigated. The power low and scale invariance theory was used to identify the distribution and evolution of TAFs. Gini coefficients were used to investigate the inequality of TAFs and explore the hot spots of attacks. It indicated that the frequency-fatality followed a power law distribution and had scale invariance. A smaller scaling exponent of power law corresponded to a slow decrease of frequency along with the increase of fatalities. Targets of transportation and private citizens, regions of Sub-Sahara Africa and Middle East and North Africa were associated with high fatality level. The inequality studies showed that TAFs were threatening more and more regions. TAFs tend to target the particular objectives such as business and private citizens. Comparing to the conventional fire, TAFs would cause more fatalities. This study will enable civilians and policymakers to predict the terrorist attack fires.
\end{abstract}

Keywords: Terrorist attack fire; Power law; Gini coefficient; Risk analysis

\section{摘要}

基于全球恐怖袭击数据库, 利用幂律分布和标度理论 分析了恐怖袭击火灾 “频率-死亡人数” 的关系和演 变趋势。结果表明 “频率-死亡人数” 服从幂律分布, 标度指数越小说明发生高死亡恐怖袭击火灾的概率 越大; 袭击目标中的交通系统和平民，区域中的撒哈
拉以南非洲、中东和北非与高死亡恐怖袭击火灾相 关。利用基尼系数和 Lorenz 曲线分析恐怖袭击火灾 的空间不均衡性, 并得到了恐怖袭击火灾的热点因素 和热点区域。基尼系数越小, 表明恐怖袭击火灾在空 间上越分散, 遭受袭击的范围较广; 得到了该类袭击 的热点目标为商业设施和平民。研究结果有助于相关 部门预测恐怖袭击火灾。

关键词: 恐怖袭击火灾; 幂律分布; 基尼系数; 风险 分析

\section{Introduction}

The 9/11 attack indicates that the world is far from tranquil, and people are still under threat in one way or another. Terrorism is a complex social phenomenon, which has become one of the most serious threats to international peace and security. Terrorist attacks harm people's lives and property, and also affect the social stability; terrorism is often characterized by bloody violence or aggressive threats [1], such as the 9/11 event, killing more than 2,700 persons. In Sweden, there are many terrorist attacks on rail-bound traffic, and the government responses to the attacks by inter-organizational collaboration [2]. Chow suggested that more evacuation exits should be provided in a super tall residential complex to response to the terrorist attacks [3].Some scholars also investigated the objectives and the fatalities of terrorism $[4,5]$.

Since 2005, the National Consortium for the Study of Terrorism and Responses to Terrorism (START) has begun to collect and maintain the global terrorism database (GTD); GTD records the global terrorist 


\section{Risk Analysis and Crisis Response in Big Data Era (RAC-16)}

incidents from 1970 to now [6]. There are 113,114 incidents and 243,520 fatality records. According to GTD, terrorist attacks occur through thirteen categories of weapons, of which incendiary (fire-related weapons) is a special type. The records of incendiary rank the third in the wake of firearms and explosives. Incendiary is defined as a fire-related weapon that is capable of catching fire, causing fire, or burning readily and produces intensely hot fire when exploded. There are three major types of incendiary: arson, flame thrower, and gasoline or alcohol. Through the literature research, little attention has been paid to incendiary weapons which are defined as fire-related weapons in this study. There are 8,018 incidents and 3,396 fatalities caused by incendiary weapons. It is hard to escape for citizens under TAFs, for example, on August 12, 2009, the fanatics burned around 35 houses and killed up to 70 civilians in Pakistan; and on January 1, 2008, tribal militia burned a church to the ground killing all 50 people inside in Kenya.

Fire and emergency workers and scholars have understood the mechanism of fire and the leading causes of death. Many researchers have been conducted to fire statistics and urban fire $[7,8,9,10]$. Unfortunately, they neglected the incidents and fatalities of fires caused by terrorists. Based on GTD, TAFs will be picked out and the targets and regions of TAFs will be discussed According to the statistics data, the hidden information of fires can be explored [11, 12].

The study aims to provide a unique perspective on the TAFs, to explore the distribution characteristics of fatalities, and investigate the variation trends of TAFs The following questions will be analyzed: Which kinds of targets will be attacked by incendiary weapons?, What distributions do the fatalities obey?, and How is the inequality of attack targets in space-time?. The effort will help to establish the baseline facts about TAFs, and therefore, the most useful countermeasures and research should be taken to TAFs.

\section{Data and methods}

\subsection{Data}

The terrorist attack incidents caused by incendiary weapons are chosen as the research subject explicitly.
Incendiary is defined that a fire-related weapon that is capable of catching fire, causing fire, or burning readily and produces intensely hot fire when exploded. There are three major types of incendiary: arson/fire, flame thrower, and gasoline or alcohol.

Table 1 Data of TAFs for 22 targets

\begin{tabular}{clcc}
\hline No & Target & Number & Death \\
\hline 1 & Business & 2235 & 670 \\
2 & Government (General) & 988 & 104 \\
3 & Police & 345 & 117 \\
4 & Military & 304 & 56 \\
5 & Abortion Related & 189 & 2 \\
6 & Airports \& Aircraft & 103 & 3 \\
7 & Government (Diplomatic) & 277 & 45 \\
8 & Educational Institution & 432 & 41 \\
9 & Food or Water Supply & 19 & 2 \\
10 & Journalists \& Media & 126 & 3 \\
11 & Maritime & 8 & 0 \\
12 & NGO & 44 & 8 \\
13 & Other & 13 & 8 \\
14 & Private Citizens \& Property & 1373 & 1720 \\
15 & Religious Figures/Institutions & 290 & 96 \\
16 & Telecommunication & 142 & 21 \\
17 & Terrorists/Non-State Militia & 15 & 80 \\
18 & Tourists & 20 & 35 \\
19 & Transportation & 987 & 342 \\
20 & Unknown & 16 & 2 \\
21 & Utilities & 54 & 28 \\
22 & Violent Political Party & 38 & 13 \\
& Total & 8018 & 3396 \\
\hline
\end{tabular}

Table 2 Data of TAFs for 13 regions

\begin{tabular}{clcc}
\hline No & Region & Number & Death \\
\hline 1 & North America & 791 & 10 \\
2 & Central America \& Caribbean & 456 & 72 \\
3 & South America & 992 & 164 \\
4 & East Asia & 229 & 32 \\
5 & Southeast Asia & 440 & 164 \\
6 & South Asia & 1265 & 702 \\
7 & Central Asia & 3 & 4 \\
8 & Western Europe & 2511 & 128 \\
9 & Eastern Europe & 53 & 5 \\
10 & Middle East \& North Africa & 745 & 701 \\
11 & Sub-Saharan Africa & 443 & 1405 \\
12 & Russia \& the Newly Independent & 49 & 9 \\
& States & 41 & 0 \\
13 & Australasia \& Oceania & 8018 & 3396 \\
\hline
\end{tabular}

To conduct a comprehensive study, 22 targets and 13 regions are selected. Table 1 and Table 2 provide the statistical data of TAFs. 8018 incidents that resulted in 3396 fatalities are available for the global countries from 1970 to 2012. The data for analysis are all 
obtained from GTD. Business is the most endangered by incendiary weapons, whereas, when terrorists target private citizens and property, it would present the most fatalities. Moreover, obvious regional characteristics can be identified that nearly half of the total incidents occurred in Western Europe and South Asia; more fatalities will be caused once the attacks occur in Sub-Saharan Africa.

\subsection{Methods}

Given $\mathrm{x}$ denotes the fatalities of terrorist attacks, and $\mathrm{P}(\mathrm{x})$ means the frequency of a special severity. If the distribution follows a power law, the probability function is

$$
p(x)=C^{\prime} x^{\alpha^{\prime}}
$$

Then we can get the probability $\mathrm{P}(\mathrm{X} \geq \mathrm{x})$ in which $\mathrm{X}$ has a value greater than or equal to $\mathrm{x}$, its cumulative probability distribution function:

$$
\begin{aligned}
& P(X \geq x)=C^{\prime} \int_{x}^{\infty} x^{-\alpha^{\prime}} d x=\frac{C^{\prime}}{\alpha^{\prime}-1} x^{-\left(\alpha^{\prime}-1\right)} \\
& \text { Taking } C=\frac{C^{\prime}}{\alpha^{\prime}-1} \text { and } \alpha=\left(\alpha^{\prime}-1\right), \text { Eq. (2.2) }
\end{aligned}
$$
equivalent to

$$
P(X \geq x)=C x^{-\alpha}
$$

The function $P(X \geq x)$ also follow power law. Taking logarithmic function of both sides of Eq. (4), it is equivalent to:

$$
\ln P(X \geq x)=\ln \left(C x^{-\alpha}\right)=\ln C-\alpha \ln x
$$

If $\mathrm{P}(\mathrm{X} \geq \mathrm{x})$ follows a power law, it is fitted to a linear by least-squares linear regression on log-log plot [13] The constant $\alpha$ is scaling exponent, which can reflect the extent of frequency decreases as the fatalities becomes higher. The relationships between fatalities and factors can be investigated by scaling exponents.

The inequality of TAFs can be identified by Gini coefficient and Lorenz curve [14]. In this study, the Lorenz curve is the plot of the cumulative percentage of incidents against the cumulative percentage of factors (target and region). The Lorenz curve would strictly follow the diagonal line when the incidents are exactly equal in different factors. If all the incidents only occur in one particular factor, the Lorenz curve would coincide with the $\mathrm{X}$-axis throughout except for the last factor where the curve jumps to the right uppermost point $(1,1)$. The Gini coefficient is calculated by the ratio of the area $\mathrm{A}$ to $(\mathrm{A}+\mathrm{B})$, or twice the area between the Lorenz curve and the diagonal line (Fig.1). A larger Gini coefficient means a more inequality of incidents, and the differences between multiple Gini coefficients can confirm the evolution of the analysis cases.

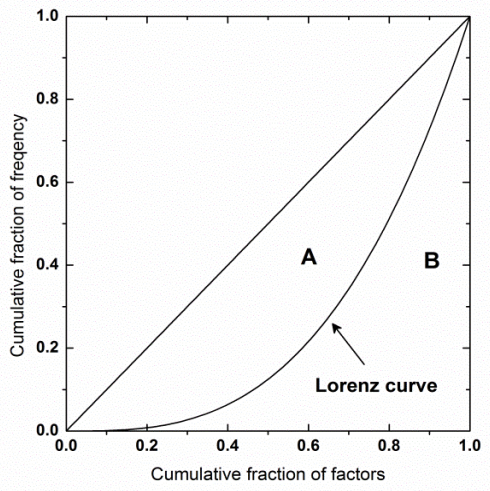

Fig.1 Lorenz curve and Gini coefficient

\section{Results and discussion}

The fatality level of TAFs is taken as $\mathrm{x}$-axis and the cumulative percentage of incidents with more than a particular severity size is y-axis. Fig.2 show that fatalities-frequency follows a power law with a scaling exponent $\alpha=1.03 \pm 0.02$. The fitting linear is $\log \mathrm{P}(\mathrm{X} \geq \mathrm{x})$ $=1.03 \times \log \mathrm{x}+0.14$. The incidents with low fatalities occur frequently, whereas the incidents with high fatality at a small probability. The results indicate that although the probability of TAFs with high fatalities is small, such attacks may still occur. Thus it increases the difficulty of predicting the consequences of TAFs and requires individuals to consider the worst situations.

The terrorists may target all valuable objectives. In this study, five targets with the most fatalities or incidents are analyzed. Considering the similarity of targets, government (general) and government (diplomatic) is merged into one category of government, and police and military are merged into police/military. Fig. 3 shows the total fatalities distributions for business, private citizens and property, government, transportation, and police/military. All the targets follow a power law and these distributions themselves exhibit 


\section{Risk Analysis and Crisis Response in Big Data Era (RAC-16)}

scale invariance. Business, which covers the most TAFs, follows a power law with a scaling exponent of $1.01 \pm 0.05$. Fig. 3 shows that the lower tail of Fig. 2 is obviously caused by some property of private citizens which covers the largest fatalities. Different target types exhibit distinct scaling exponents. A small scaling exponent indicates that the frequency decreases more slowly as the size of severity increase. Thus, transportation and private citizens have the largest associated with the maximum severity, whereas business has the smallest. The phenomenon may be due to the high person density of transportation and the lack of self-protection consciousness for private citizens.

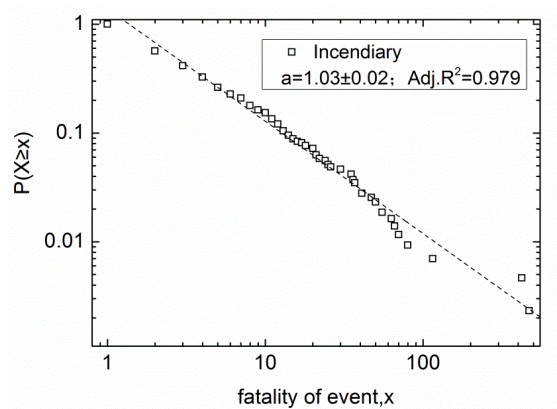

Fig.2 Frequency-fatality distributions of TAFs

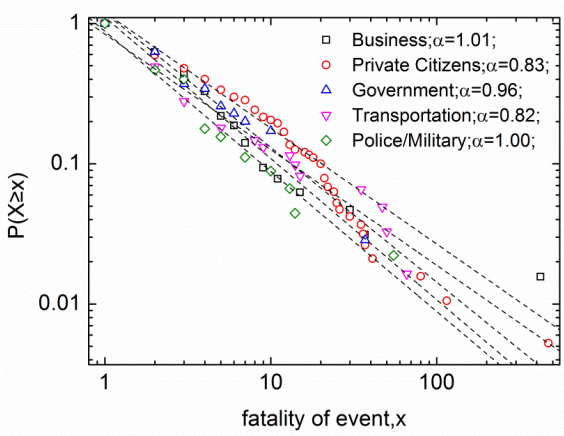

Fig.3 Frequency-fatality distributions of targets

In this study, thirteen regions are recorded according to the GTD. Some regions cannot be fitted by power law because of the lack of statistic data. Fig. 4 depicts the five regions with the most incidents or fatalities. The fitting lines vary in the five regions. The scaling exponents of Western Europe and South America are larger than other three regions, and Sub-Saharan Africa has the smallest scaling exponent with $\alpha=0.71 \pm 0.04$. The results indicate that TAFs in Sub-Sahara Africa have the largest associated maximum fatalities; Table 2 show that the number of incidents in Western Europe is 5.6 times higher than Sub-Sahara Africa, whereas, the fatalities of Sub-Sahara Africa are nearly 11 times higher than that of Western Europe. This may be due to the differences in countermeasure against terrorism and the social stability in these regions.

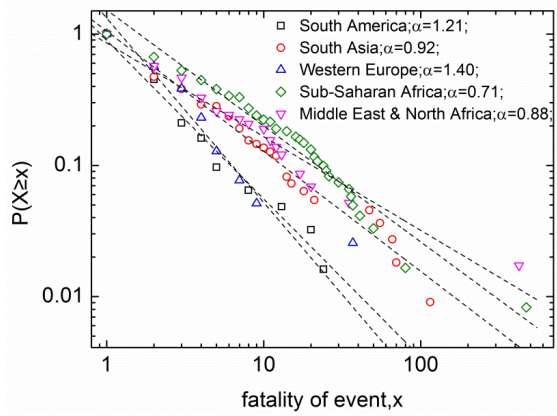

Fig.4 Frequency-fatality distributions of regions

Fig. 5 shows the power law distribution for the three periods. The scaling exponents increase first and then decrease. It indicates an improvement for TAFs during 1989-2000, whereas becomes worse after 2001. The number of TAFs is $2,182,3,330$, and 1,927 for three periods, and corresponds to $890,1,058$, and 1,422 fatalities. The reduction of frequency has not reduced the threat of TAFs.

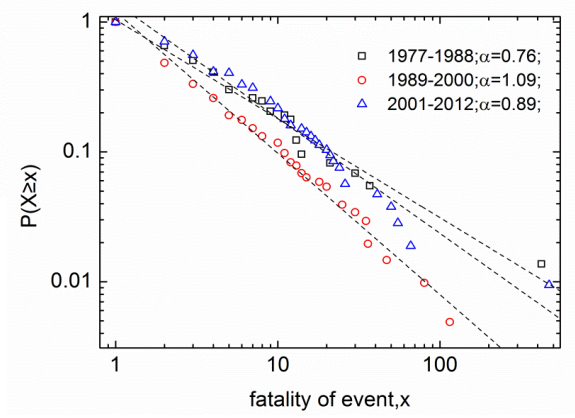

Fig.5 Frequency-fatality distributions of the three periods 
Risk Analysis and Crisis Response in Big Data Era (RAC-16)

Actually, Lu et al. [15] have investigated the fires with three or more fatalities in China and other countries, and the results indicates that the frequency-size follow power law distribution. Six factors, such as place, fire cause, the time of day, season, year and location are considered to obtain the influence on the frequency-fatality distribution and the factors associated with high fatalities are identified. However, all the scaling exponents of these power law distributions are more than 2.0. The smallest scaling exponents are U.S non-residential fatality fires and the fire of Zhejiang province in China; the values are 2.66 and 2.42. Compared to Lu's results, the scaling exponents of TAFs are far less, which means TAFs are more likely to be associated with high fatalities.

To understand the evolution of TAFs further, the Gini coefficient and Lorenz curve are used. Fig. 6 and Fig.7 indicate that the Gini coefficients of region decrease from the period of 1977-1988 to 1989-2000, and increase after 2000. The smaller Gini coefficient of 1989-2000 means a concentrated trend for targets, whereas more regions suffer TAFs after 2001 because of the increase of Gini coefficient. The phenomenon is consistent with the results of Fig.5. The Lorenz curve is plotted by sorting the regions according to the number of incidents. Thus, the hot spots of regions with more TAFs can be identified from the Lorenz curve; the top three regions are summarized in Table 3. An obvious trend can be found that TAFs evolved from Western Europe, South America, and Central America \& Caribbean to South Asia and Southeast Asia. During period from 1977 and 1988, only $4.08 \%$ of the total attacks occurred in South Asia and Southeast Asia, whereas the percentage rises up to $48.93 \%$ during the period from 2001 to 2012 .

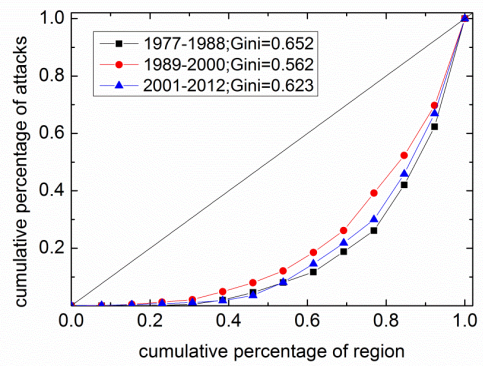

Fig.6 The Lorenz curve of regions from 1977 to 2012
Fig.6 also depicts the Gini coefficients of target for three 12-year periods, and 2001-2012 have the smallest Gini coefficient which means TAFs tent to concentrate in some particular targets. The Lorenz curve of 2001-2012 grow more slowly before the $70 \%$ of cumulative percentage of target than other two periods, whereas it increases rapidly after $70 \%$ and exceeds other two periods. Thus, the targets at the right up of Fig. 6 become the hot spots of TAFs during the period from 2001 to 2012, namely, business, private citizens and property, government (general), educational institution, and transportation. The top three targets are shown in Table 3. The hot spots indicate that the terrorists target to civilians

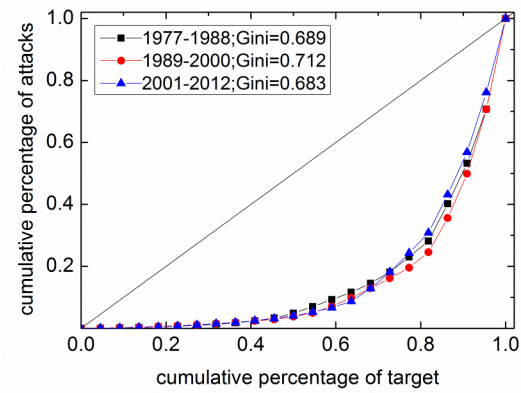

Fig.7 The Lorenz curve of targets from 1977 to 2012

\section{Conclusions}

This article discusses the frequency-fatality distribution and evolution of terrorist attack fires (TAFs) based on the statistical data. The power law distribution of frequency-fatality is confirmed. Regions and targets of FTAs are analyzed. The Gini coefficient and Lorenz curve are introduced as an analytical tool to investigate the evolution of TAFs and identify the hot spots of targets and regions.

The results indicate that the frequency-fatality of TAFs follows a power law distribution. The scaling exponents can reflect the decreasing degree of frequency along with the increasing of fatality level. Targets of transportation and private citizen and property, regions of Sub-Sahara Africa and Middle East and North Africa tend to be associated with high fatalities. By using the Gini coefficient, the inequality of fire-related emerge, and the results show that the 


\section{Risk Analysis and Crisis Response in Big Data Era (RAC-16)}

fire-related attacks tend to occur in more regions, whereas they begin to target some particular objectives, especially civilians. When compared with the Lu's study on fire fatalities, the power law distributions of fire-related terrorist attack have smaller scaling exponents which means they are more likely to be associated with high fatalities. This study aims to give a novel perspective to TAFs, attract more individuals to focus on the fire threat, and avoid or prevent threat of TAFs.

Table 3 The hot spots of TAFs and cumulative percentage

\begin{tabular}{|c|c|c|c|c|c|c|}
\hline \multirow{2}{*}{ Items } & \multicolumn{2}{|l|}{$1977-1988$} & \multicolumn{2}{|l|}{$1989-2000$} & \multicolumn{2}{|l|}{ 2001-2012 } \\
\hline & Top 3 & $\%$ & Top 3 & $\%$ & Top 3 & $\%$ \\
\hline \multirow[t]{3}{*}{ Region } & Western Europe & 37.67 & Western Europe & 30.27 & South Asia & 33.01 \\
\hline & South America & 20.26 & South Asia & 17.34 & Western Europe & 20.99 \\
\hline & $\begin{array}{l}\text { Central America \& } \\
\text { Caribbean }\end{array}$ & 15.90 & $\begin{array}{l}\text { Middle East \& North } \\
\text { Africa }\end{array}$ & 13.13 & Southeast Asia & 15.92 \\
\hline Total & & 73.83 & & 60.74 & & 69.92 \\
\hline \multirow[t]{3}{*}{ Target } & Business & 29.24 & Business & 29.31 & Business & 23.87 \\
\hline & Transportation & 17.46 & $\begin{array}{l}\text { Private Citizens \& } \\
\text { Property }\end{array}$ & 20.75 & Private Citizens \& Property & 19.30 \\
\hline & Government (General) & 13.11 & Transportation & 14.38 & Government (General) & 13.65 \\
\hline Total & & 59.81 & & 71.44 & & 56.82 \\
\hline
\end{tabular}

Terrorism and Responses to Terrorism (START). Global Terrorism Database [Data file]. Retrieved from http://www.start.umd.edu/gtd.2012.

\section{Acknowledgements}

This study was supported by the National Natural Science Foundation of China (No.71403254) and the Basic Scientific Research Projects of Tianjin Fire Research Institute of MPS (No.2016SJ-A-23).

\section{致谢}

本研究得国家自然科学基金(71403254)和公安部天 津消防研究所基本科研业务费(2016SJ-A-23)的资助。

\section{References}

[1] Kaya D D, Wehreyt F, Grant A K, et al., More freedom, less terror?: Liberalization and political violence in the Arab world. Rand Corporation, 2008.

[2] Strandh V, Sweden's Capacity to prepare and respond to a terrorist attack on rail-bound traffic -promising practices and obstacles to inter-organizational collaboration. Journal of Risk Analysis and Crisis Response. 5(4): 215-225, 2015

[3] $\mathrm{K} \mathrm{C} \mathrm{W,} \mathrm{Evacuation} \mathrm{in} \mathrm{a} \mathrm{supertall} \mathrm{residential}$ complex. Journal of applied fire science. 13(4): 291-300, 2005.

[4] Keeney G L and Von Winterfeldt D, Identifying and structuring the objectives of terrorists. Risk Anal. 30(12): 1803-1816, 2010

[5] Shapira S C, Adatto-Levi R, Avitzour M, et al., Mortality in terrorist attacks: A unique modal of temporal death distribution. World Journal of Surgery. 30(11): 2071-2079, 2006.

[6] START, National Consortium for the Study of
[7] Hasofer A M and Thomas I, Analysis of fatalities and injuries in building fire statistics. Fire Safety Journal. 41(1): 2-14, 2006.

[8] Holborn P G, Nolan P F, and Golt J, An analysis of fatal unintentional dwelling fires investigated by London Fire Brigade between 1996 and 2000. Fire Safety Journal. 38(1): 1-42, 2003.

[9] Chi J H, Hang Y L, Shen JH, et al., Building fire situation and characteristic analysis based on fire statistics of investigation results in Taiwan. Journal of applied fire science. 12(4): 263-289, 2004.

[10] Wang J H, Dynamics of urban fire correlations with detrended fluctuation analysis. Journal of Risk Analysis and Crisis Response. 1(2): 126-132, 2011.

[11] Li G, Lu S, Mei P, et al. Influences of time, location, and cause factors on the probability of fire loss in china a correspondence analysis. Fire Technology. 50(5): 1181-1200, 2014.

[12] Clauset, Aaron; Wiegel, Frederik W. A generalized aggregation-disintegration model for the frequency of severe terrorist attacks. Journal of Conflict Resolution. 54(1): 179-1976, 2010.

[13] Newman M E J, Power laws, Pareto distributions and Zipf's law. Contemporary physics. 46(5): 323-351, 2005

[14] Alvaredo F, A note on the relationship between top income shares and the Gini coefficient. Economics Letters. 110(3): 274-277, 2011.

[15] Lu S, Mel P, Wang J, et al., Fatality and influence factors in high-casualty fires: A correspondence analysis. Safety Science. 50(4):1019-1033, 2012. 